\title{
ANÁLISE DISCURSIVA DO PREFÁCIO DO DICIONÁRIO DE LÍNGUA PORTUGUESA, DE EVANILDO BECHARA
}

\author{
RODRIGO ALVES SILVA; LAYANA KELLY PEREIRA DE HOLANDA
}

\author{
Universidade Federal do Piauí - UFPI
}

rodrigoalvessilva@hotmail.com.br ; layana_holanda@hotmail.com

\begin{abstract}
Resumo. Este trabalho pretende analisar, à luz da Análise de Discurso, o prefácio do Dicionário de língua portuguesa, de Evanildo Bechara. O objetivo principal é investigar como o prefácio produz sentido, levando em conta as seguintes categorias: o sujeito enunciador, as condições de produção, a formação discursiva e o sujeito "outro". Para tanto, fez-se uma breve apresentação de conceitos fundamentais da Análise de Discurso, baseado em Courtine (2009), Mussalim (2003), Orlandi (2006) e Pêcheux (2006). Além disso, mostrou-se, brevemente, como o dicionário pode ser tomado como objeto de discurso, baseado em Nunes (2006). Sendo assim, o dicionário constrói sua significação por meio da interação entre interlocutores. $\mathrm{O}$ sujeito-autor produz o seu discurso a partir de uma posição social, regulado por uma formação discursiva e influenciado pelas condições de produção. Uma análise preliminar permitiu reconhecer, entre outras coisas, que o discurso no prefácio é feito mediante o imaginário de um público leitor (alunos do ensino médio) e a partir de uma formação discursiva inserida no contexto de valorização do uso de dicionários na escola (proposta do PNLD).
\end{abstract}

Palavras-chave: Análise de Discurso; prefácio; dicionário.

\begin{abstract}
This paper aims to examine the preface to a dictionary of the Portuguese language by Evanildo Bechara, according to Discourse Analysis. The main objective is to investigate how the preface makes sense, taking into account the following categories: the subject that speaks, production conditions, the discursive formation and the subject known as the "Other." For this purpose, there was a brief presentation of the basic concepts of Discourse Analysis, based on Courtine (2009), Mussalim (2003), Orlandi (2006) and Pêcheux (2006). Moreover, it was showed up briefly how this dictionary can be taken as the object of speech, based on Nunes (2006). Thus, the dictionary builds its meaning through interaction among speakers. The subjectauthor produces his speech from a social position regulated by a discursive formation and influenced by production conditions. Preliminary analysis above demonstrates that the discourse in the preface is done by the imagination of a reader audience (high school students) and from a discursive training within the context of appreciation of the use of dictionaries in school (proposed by the National Textbook ProgramPNDL), among other things.
\end{abstract}

Keywords: Discourse Analysis; preface; dictionary.

\section{Introdução}

Este trabalho pretende analisar, à luz da Análise de Discurso, o prefácio do Dicionário de língua portuguesa, de Evanildo Bechara. Segundo Nunes (2010), os prefácios, textos introdutórios de determinadas obras, inclusive dos dicionários, 
"constituem um material fundamental para a análise das condições de produção do discurso e da posição do lexicógrafo" (p. 33).

É importante definir que dicionário é muito mais do que apenas um instrumento linguístico. Ele se constitui, segundo Nunes (2010), como um objeto discursivo, no qual o saber sobre a língua constitui-se, instaura-se, organiza-se, reorganiza-se; bem como é retomado, é construído e é desestabilizado, produzindo efeitos de sentidos. O dicionário é, pois, um espaço de construção, desconstrução e reconstrução de sentidos, um lugar em que o sentido pode ser outro. O sujeito que escreve o prefácio do dicionário leva em conta o papel dele no mundo, uma vez que a língua é uma mediação entre o mundo e o homem.

O objetivo principal deste trabalho é investigar como o prefácio produz sentido, levando em conta as seguintes categorias: o sujeito enunciador, as condições de produção, a formação discursiva e o sujeito "outro".

O dicionário é tomado como um objeto de discurso, pois sua significação é construída por meio da interação entre os interlocutores. $\mathrm{O}$ sujeito enunciador produz o seu discurso a partir de uma posição social, regulado por uma formação discursiva e influenciado pelas condições de produção. Esses conceitos são abordados na seção seguinte.

\section{Fundamentação Teórica}

\subsection{A constituição da Análise de Discurso}

Nesta seção, traça-se um breve percurso histórico da constituição da Análise de Discurso. Essa área remonta aos estudos da retórica por Aristóteles na Antiguidade. No entanto, seu surgimento como ciência se dá muito tempo depois, quando os estudos sobre a língua ganharam status de cientificidade, no início do século XX, com o surgimento da Linguística. Inicialmente, com os estudos de Saussure e, posteriormente, com Chomsky, a língua era vista como uma estrutura, e, para estudá-la, seria dispensável o sujeito falante, bem como os aspectos sociais.

Em meio a esse contexto teórico, surgem, na França, em 1960, os estudos sobre o discurso. Um de seus primeiros estudiosos é Michel Pêcheux, o qual acredita que o discurso assume uma materialidade por meio da linguagem. Além disso, o autor pontua que a linguagem não serve apenas para a comunicação, mas também para "propagar" ideologias.

A Análise do Discurso (AD) é uma área que se configurou marcadamente na década de 1960, na França, a partir das contribuições de Jean Dubois e Michel Pêcheux. Nesse ínterim, uma disciplina que tem como objeto de estudo o discurso, se apresenta como necessária, visto que o estruturalismo já se encontrava em um desgaste explícito.

Os postulados da Análise de Discurso (AD) têm base, principalmente, no estruturalismo, no materialismo histórico e na psicanálise. O materialismo histórico, 
proposto inicialmente por Karl Marx, foi estudado e reformulado por Althusser, o qual via que a ideologia não deve ser concebida apenas como ideias, mas como formas materiais, que reproduzem as relações de produção (MUSSALIM, 2003).

O estruturalismo linguístico influenciou os estudos da Análise de Discurso, porque se tinha a linguagem como o lugar da materialização do discurso, ou seja, estudando a língua, seria possível apreender a ideologia ali presente. A língua é uma mediação entre o mundo e o homem. Os estudos estruturalistas, no entanto, relegavam os aspectos relacionados ao sujeito e ao social, por isso só o estruturalismo não foi suficiente. Sendo assim, ao entender que língua não serve apenas para comunicar, mas também para produzir efeitos de sentido, Pêcheux acreditava que os significados na língua se constroem social, ideológico e historicamente.

A psicanálise, sobretudo a de Lacan, também influenciou o estabelecimento da AD. Conforme Mussalim (2003), com a descoberta do inconsciente, por Freud, o sujeito deixa de ser visto como homogêneo e passa a ser visto como um sujeito heterogêneo, dividido entre o consciente e o inconsciente. Para Lacan, o inconsciente se estrutura como linguagem e interfere no discurso do sujeito. $\mathrm{O}$ inconsciente é permeado pelo discurso do Outro. Dessa maneira, o discurso do sujeito seria produto de significados vindos do inconsciente, o qual é produto de outros significados.

Lacan também se baseou no estruturalismo de Saussure para estabelecer sua ideia de sujeito. Assim como Saussure concebia que o valor do signo se dava pelo critério diferencial e não substancial, ou seja, um signo é um porque não é outro, Lacan também se baseou nessa concepção para construir o conceito de sujeito: o sujeito só se define em relação ao outro. É no inconsciente que o Outro se encontra. Ele pode ser o discurso do pai, da mãe, dentre outros. $O$ sujeito se relaciona com o outro na medida em que este "ocupa uma posição de domínio com relação ao sujeito, é uma ordem anterior e exterior a ele, em relação à qual o sujeito se define, ganha identidade" (MUSSALIM, 2003, p. 109).

Diante dessas três confluências teóricas, pode-se afirmar que a AD pressupõe a psicanálise, a linguística e o marxismo (ORLANDI, 2006). E ainda:

[...] pressupõe na medida em que se constitui da relação de três regiões científicas: a da teoria da ideologia, a da teoria da sintaxe e da enunciação, e a teoria do discurso como determinação histórica dos processos de significação. Tudo isso atravessado por uma teoria psicanalítica do sujeito. É esse o contexto teórico da análise de discurso. (ORLANDI, 2006, p. 13)

Sobre essa tríade teórica que constituiu a Análise de Discurso, Pêcheux (2006) afirma que "o efeito subversivo da trilogia Marx-Freud-Saussure foi um desafio intelectual engajando a promessa de uma revolução cultural, que coloca em causa as evidências da ordem humana como estritamente biossocial”. (PÊCHEUX, 2006, p. 45). 
Tento visto o breve contexto teórico de constituição da $\mathrm{AD}^{1}$, passa-se a uma discussão mais profícua sobre seu objeto: o discurso.

\section{$1.2 \mathrm{O}$ discurso e seus elementos constitutivos}

Com a fundação da Escola Francesa da Análise do Discurso, tendo a frente a figura de Michel Pêcheux, o discurso se estabelece na associação entre a história e a ideologia. O teórico explicita que a história determina os processos de significação. Assim, ele inclui a historicidade no estudo da ciência linguística e afirma que as ciências sociais têm relação direta com a ideologia que as funda.

O discurso, objeto de estudo da $\mathrm{AD}$, não é apenas uma transmissão de informação, mas um efeito de sentido entre locutores (ORLANDI, 2006). Sendo assim, para a AD, não existe a relação entre o locutor que produz uma mensagem e a transmite, por meio de um código (a língua), para um interlocutor que a decodifica, mas sim efeitos de sentidos que se constituem mediante aos fatores externos (o sujeito, a história, a situação, por exemplo). O que ocorre, para a $\mathrm{AD}$, é que os dois (emissor e receptor) realizam o processo de significação ao mesmo tempo. Nesse processo de significação, o que se produz não é apenas uma informação, mas um discurso carregado de sentido.

A AD considera que a linguagem não é transparente. Não há uma relação direta entre língua, mundo e pensamento. A linguagem é carregada de sentidos, que são construídos por meio da história e da ideologia. Por isso "o discurso é a materialidade específica da ideologia e a língua é a materialidade específica do discurso" (ORLANDI, 2006, p. 17).

O próprio Pêcheux defende a opacidade do discurso, ou seja, o sentido, para ele, não está inerente à palavra, mas é construído nas relações em que tais palavras estabelecem numa formação discursiva. Dessa forma, Pêcheux (2006) concebe o discurso como estrutura ou acontecimento. A linguagem é o meio pelo qual o discurso se materializa, portanto, é a estrutura do discurso. No entanto, o sentido não é unívoco, para cada palavra que compõe um discurso não há um correspondente externo. O sentido é, pois, construído a partir de um acontecimento, que pode ser extralinguístico.

O discurso não é estável em sua significação, mas se caracteriza pela instabilidade marcada pela tensão, pelo conflito e pela mudança de acontecimento. Isso corrobora o fato de que o sentido não está inerente ao discurso, mas se constrói e se ressignifica, como afirma Pêcheux (2006):

[...] todo enunciado é intrinsecamente suscetível de tornar-se outro, diferente de si mesmo, se deslocar discursivamente de seu sentido para derivar para outro (a não ser que a proibição da interpretação própria ao logicamente estável se exerça sobre ele explicitamente). Todo enunciado, toda sequência de enunciados é, pois, linguisticamente

\footnotetext{
${ }^{1}$ Ressalta-se que, dentro da Análise de Discurso, existem outras correntes teóricas, como a de Chareaudau, Maingueneau, van Dijk, Fairclough, Wodak etc. No entanto, o foco do trabalho é a teoria de Pêchaux.
} 
descritível como uma série (léxico-sintaticamente determinada) de pontos de deriva possíveis, oferecendo lugar a interpretação. (PÊCHEUX, 2006, p. 53)

O autor exemplifica este fato com o enunciado "On a gagné" [Ganhamos], que teve expressividade em 10 de maio de 1981 na França, com a vitória François Mitterand nas eleições presidenciais. Esse enunciado é retomado num contexto político e remete a um contexto esportivo. Mesmo sendo o mesmo enunciado - "On a gagné" -, nesses dois distintos contextos o sentido produzido também será igualmente distinto. Portanto, o sentido é deslocado.

Em poucas palavras, Orlandi define discurso como "efeito de sentido entre interlocutores" (ORLANDI, 2003, p. 21). A Análise de Discurso se interessa, principalmente, pelos sentidos produzidos pela linguagem, e esse sentido só é produzido por que a linguagem se inscreve na história (ibdem). Conforme a autora, a AD procura não só desvendar o sentido de um discurso produzido por um objeto simbólico (enunciado, texto, pintura, música etc.), mas também compreender como os sentidos são produzidos e quais outros sentidos estão presentes no discurso em análise. Assim, ao se analisar um discurso, é necessário levar em conta as condições de produção, na qual se inscreve o discurso.

As condições de produção, conceito construído por Pêcheux, dizem respeito aos elementos extralinguísticos que contribuem para a produção do discurso, visto que é o contexto que circunda o discurso. Elas incluem o sujeito e a situação. Segundo Orlandi (2006), pode-se entender as condições de produção de duas maneiras: como contexto imediato (o aqui e o agora do dizer) e como contexto sócio-histórico, ideológico (condições sociais, históricas e ideológicas). Mesmo distintos, esses dois contextos são indissociáveis e ambos atuam concomitantemente na produção do discurso.

É importante considerar, dentro das condições de produção, a posição que o sujeito ocupa ao proferir um discurso. A posição do sujeito funciona então, segundo Pêcheux, como uma formação imaginária que media a relação entre os sujeitos. Em outras palavras, o discurso é produzido mediante um "jogo de imagens" que o locutor faz de si, do seu ouvinte e da imagem que o locutor imagina que o ouvinte faz dele. Diante disso, faz-se mister observar que, quando se fala em sujeito na Análise de Discurso, não se trata do sujeito empírico, real, de carne e osso, mas de uma posição social, da qual se tem todo um imaginário social, histórico e ideológico. A posição social tem a ver com as relações de força que se estabelecem no discurso. Conforme Orlandi (2006):

Segundo as relações de força, o lugar social do qual falamos marca o discurso com a força da locução que este lugar representa. Assim, importa se falamos do lugar de presidente, ou de professor, ou de pai, ou de filho etc. Cada um desses lugares tem sua força na relação de interlocução e isto se representa nas posições sujeito. Por isso essas posições não são neutras e se carregam do poder que as constitui em suas relações de força. (ORLANDI, 2006, p. 16).

Assim, nota-se que a posição social é um fator fundamental na significação do discurso e nas relações de força. Além disso, quando o locutor se coloca na posição de seu interlocutor e imagina como esse lhe vê, tem-se a chamada antecipação. Segundo 
Orlandi (2006), a antecipação é a principal responsável pela argumentação, pois o locutor consegue inferir, antecipadamente, a resposta de seu interlocutor.

Outro conceito ligado à produção do discurso é o interdiscurso (ou memória discursiva). $\mathrm{O}$ interdiscurso consiste no já dito, aquilo que já foi proferido em outros discursos. Segundo Orlandi (2003), é a memória discursiva que torna possível todo dizer e sustenta cada novo discurso. Dessa forma, toda palavra proferida tem sua significação ancorada nos sentidos já existentes, preestabelecidos, ou seja, "para que uma palavra tenha sentido, é preciso que ela já faça sentido" (ORLANDI, 2006, p. 18).

A noção de interdiscurso traz, como consequência, a ideia de que nenhum indivíduo profere um discurso inédito, pois tudo já foi dito. Mesmo que inconscientemente, o sujeito se apropria de discursos anteriores a ele. Como afirma Orlandi (2003):

O dizer não é propriedade particular. As palavras não são só nossas. Elas significam pela história e pela língua. O que é dito em outro lugar também significa nas "nossas" palavras. O sujeito diz, pensa que sabe o que diz, mas não tem acesso ou controle sobre o modo pelo qual os sentidos se constituem nele. (ORLANDI, 2003, p. 32)

Partindo dessa concepção, afirma-se que o sujeito é "assujeitado" pela língua e pela ideologia: "a ideologia interpela o indivíduo em sujeito e este submete-se à língua significando e significando-se pelo simbólico na história" (ORLANDI, 2006, p. 19). O assujeitamento é uma condição de todo ser humano.

O assujeitamento do indivíduo é ocasionado pelo esquecimento. Segundo Orlandi (2003), há duas formas de esquecimento: i) ideológico - aquele em que o sujeito esquece a ideologia que o determina (o interdiscurso), tem a ilusão de ser a origem do que diz e é a ordem do inconsciente; ii) enunciativo - aquele em que o sujeito constrói determinados sentidos e não outros conscientemente.

Além de o sujeito não ter um discurso próprio, ele também só enuncia seu discurso a partir de uma formação discursiva. Isto seria o que pode ou deve ser dito em uma determinada formação ideológica. Com isso, dentro de uma determinada formação ideológica, o sujeito deve proferir certos discursos e não outros. Tomando a formação discursiva cristã como exemplo, infere-se que um sujeito padre jamais diria que não se deve amar ao próximo ou que Deus não existe.

Tendo visto alguns conceitos basilares da $\mathrm{AD}$, passe-se, na seção seguinte, a estabelecer um paralelo entre a $\mathrm{AD}$ e o dicionário, objeto de análise.

\subsection{O dicionário como objeto discursivo}

Tomamos como material de análise um dicionário escolar, material produtor de sentidos e não apenas um instrumento que traz o significado das palavras. Segundo Nunes (2006), os sentidos no dicionário se estabelecem na relação entre os locutores. 
Trabalhos como o de Nunes (2006) analisam o discurso de dicionários em vários domínios lexicográficos: prefácio, verbete, nomenclatura, definição, contextualização, etimologia, marcação, dentre outros. $\mathrm{O}$ autor toma como objetos de análise dicionários brasileiros do Período Colonial, do Período Monárquico e do período de transição para a República. $\mathrm{O}$ autor também analisa a historicidade desses materiais.

Neste trabalho, pretende-se analisar o prefácio de um dicionário escolar contemporâneo: o Dicionário da língua portuguesa, de Evanildo Bechara (2011). O autor, neste caso, é o sujeito lexicógrafo². Segundo Nunes (2003), o sujeito lexicógrafo é visto, pela Análise de Discurso, não como um ou outro sujeito empírico, mas como uma posição de sujeito historicamente constituída. $\mathrm{O}$ autor afirma também que a forma sujeito lexicógrafo está relacionada à função de autor. Sendo assim, o "autor" não é o sujeito empírico, mas um sujeito construído histórico e ideologicamente. Essa posição de autor de um dicionário pode ser ocupada por um indivíduo, um grupo de indivíduos, uma editora etc.

Por fim, Nunes (2003) afirma que o dicionário é construído a partir da imagem que o lexicógrafo constrói do outro. Esse outro seria o público leitor que consulta o dicionário. Construindo a imagem do leitor, o sujeito lexicógrafo procura construir sua significação a partir do que se espera num discurso lexicográfico, a fim de atender às expectativas do outro.

No prefácio em análise, observa-se como o sujeito lexicógrafo (o autor do dicionário) constrói seu discurso a partir da imagem que ele faz do público consulente. $\mathrm{O}$ Dicionário de língua portuguesa é destinado, principalmente, a alunos do Ensino Médio. Portanto, espera-se que o sujeito lexicográfico construa seu discurso a partir da imagem que ele faz desse público específico.

\section{Concepções teórico-analíticas}

A Análise de Discurso se constitui como uma disciplina de metodologia peculiar. Há várias discussões a respeito dos procedimentos metodológicos em trabalhos dessa natureza. Consideraremos arquivo o prefácio do dicionário de Bechara, de acordo com Pêcheux. Neste trabalho, baseamo-nos, principalmente, no conceito de dispositivo analítico propostas por Orlandi (2003). Segundo ela, o dispositivo analítico diz respeito ao modo como o analista procede na análise de um texto. Para tanto, é necessário considerar alguns aspectos: a natureza dos materiais analisados, a questão colocada, as diferentes teorias dos distintos campos disciplinares etc.

Relacionando esses aspectos do dispositivo analítico ao objeto de análise deste trabalho, é possível definir que: quanto à natureza do material analisado, tem-se o prefácio; a questão colocada seria como o autor constrói o seu discurso no prefácio; e as diferentes teorias dos distintos campos disciplinares seriam a sociolinguística $e$ lexicografia pedagógica.

\footnotetext{
${ }^{2}$ Neste trabalho, tratamos autor, lexicógrafo e sujeito lexicógrafo como sinônimos, ao nos referirmos ao autor do texto em análise.
} 
A escolha desse arquivo se deu por se tratar de um texto presente em dicionário escolar, nosso objeto de pesquisa em outros trabalhos. Além disso, percebeu-se a importância de se analisar esse tipo de texto, haja visto que há trabalhos anteriores que também analisam o discurso em prefácios de dicionários, como também de livros didáticos. Para citar alguns, destacam-se o trabalho de Giacomini (2006), que analisa o prefácio do dicionário de Caldas Aulete, e os trabalhos de Cargnelutti (2008) e de Oliveira (2014), os quais analisam o prefácio da gramática de Cegalla e de um livro didático de português, respectivamente. Em análises como essas, é possível perceber como o sujeito autor constrói seu discurso em prefácios. Para dar continuidade a pesquisas de análise discursiva, este trabalho se propõe, como já dito anteriormente, a analisar o prefácio do Dicionário de língua portuguesa, de Evanildo Bechara. A seguir, passe-se à análise do prefácio escolhido.

\section{Análise do prefácio}

O objeto de análise deste trabalho é o prefácio do Dicionário da língua portuguesa, de Evanildo Bechara, publicado em 2011. Para proceder a análise, apresentase, a seguir, o texto na íntegra.

\section{PREFÁCIO}

O vocabulário é a janela da língua que se abre para os objetos e as ideias que povoam o mundo contemporâneo dos falantes. Inserido o dicionário nas atividades de sala de aula, oferece aos alunos do ensino médio oportunidade de lhes facilitar um aprendizado reflexivo e criador no mundo significativo das palavras.

Construído com um número de verbetes compatível com a idade e o desenvolvimento cultural dos alunos, este dicionário abrange um horizonte largo de temas que estimulam a curiosidade intelectual dos jovens e lhes agudizam o cabedal de cultura, tais como as artes, as linguagens, as religiões, a política, as ciências, as tecnologias, o meio ambiente, os esportes, as profissões, que correm nos livros em geral, na literatura, e nos meios de comunicação, tanto impressos, quanto eletrônicos. Este repertório lexical se acha enriquecido com a presença de gírias e estrangeirismos de uso corrente, incluindo-se aí as abreviaturas e siglas.

Esta obra, como ferramenta de formação, educação e apoio às iniciativas de inclusão social, busca propagar conceitos e princípios éticos, tanto no conteúdo dos verbetes e exemplos, como nas indicações dos níveis de linguagem, e na breve orientação, na página a seguir, sobre o comportamento nas redes sociais.

$\mathrm{Na}$ estruturação dos verbetes, mereceu atenção especial o significado fundamental da palavra com suas franjas semânticas mais cristalizadas, das diferentes regiões do Brasil, em diversos contextos, estendendo-se em empregos fraseológicos. No verbete também não faltam chamadas para a correta flexão nominal e verbal, para a correção ortoépica e prosódica.

Redigido em obediência ao novo Acordo Ortográfico e atento às normas da língua portuguesa e aos usos correntes entre os brasileiros, este dicionário traz ainda vários adendos, entre eles uma Gramática Básica, o que torna a obra ainda mais completa. No final do dicionário há também uma lista, em ordem alfabética, com as entradas que tiveram a grafia alterada pelo novo Acordo Ortográfico, o que possibilita soluções de dúvidas ortográficas de forma clara e rápida.

Evanildo Bechara 
No prefácio acima, é possível perceber uma breve apresentação que o autor faz de seu dicionário. Nessa apresentação, nota-se que o autor procura apontar as qualidades da obra, os pontos mais relevantes que ela contém. Isso pode ser visto nos seguintes trechos:

Construído com um número de verbetes compatível com a idade e o desenvolvimento cultural dos alunos, este dicionário abrange um horizonte largo de temas [...];

Este repertório lexical se acha enriquecido com a presença de gírias e estrangeirismos de uso corrente [...];

Redigido em obediência ao novo Acordo Ortográfico e atento às normas da língua portuguesa e aos usos correntes entre os brasileiros, este dicionário traz ainda vários adendos $[\ldots .$.$] ".$

Observando os trechos destacados, infere-se que o autor procura propagandear o dicionário, apresentando o que ele tem de vantagens: grande número de verbetes, de diferentes temas, incluindo gírias e estrangeirismos; obediência ao novo Acordo Ortográfico e a presença de adendos, que são anexos com assuntos sobre gramática e sobre a nova ortografia.

Retomando a noção de condição de produção, pode-se afirmar que o texto em questão se insere num contexto social, político e educacional em que se reconhece a importância do uso do dicionário nas escolas (RANGEL, 2012). O Ministério da Educação tem elaborado políticas de avaliação e distribuição de dicionários nas escolas de educação básica, nos últimos anos. O mais recente empreendimento desse tipo foi feito em 2012, em que o próprio Dicionário de língua portuguesa, de Evanildo Bechara, objeto de estudo deste trabalho, constava como um dos dicionários a serem avaliados pelo Programa Nacional do Livro Didático - Dicionários. O PNLD exige, entre outras coisas, que os dicionários contenham uma linguagem acessível aos alunos, com um repertório lexical próprio para a idade deles. Sendo assim, todo esse contexto de políticas educacionais pode funcionar como condição de produção do discurso.

Essa influência do contexto político-educacional pode ser visto no seguinte trecho:

Inserido o dicionário nas atividades de sala de aula, oferece aos alunos do ensino médio oportunidade de lhes facilitar um aprendizado reflexivo e criador no mundo significativo das palavras.

Observa-se, além disso, que, diante da formação ideológica de que o "dicionário é importante no processo de ensino-aprendizagem", o discurso desse trecho reproduz essa ideologia. Ou seja, o autor enuncia a partir da formação discursiva na qual está inserido: como um lexicógrafo, o autor afirma, como visto no trecho, que o dicionário, de fato, exerce influência positiva na aprendizagem dos alunos.

Ainda sobre esse excerto, nota-se o Outro, a partir do qual o sujeito lexicógrafo constrói o seu discurso. Esse Outro está explícito e são "os alunos do ensino médio", para quem é destinado o dicionário. Como afirma Nunes (2003), a posição-sujeito lexicógrafo projeta um público leitor. Destarte, ao projetar os discentes do Ensino Médio, o lexicógrafo constrói o discurso afirmando que o dicionário irá lhes oferecer "um aprendizado reflexivo e criador no mundo significativo". 
Nesse entremeio e conforme Orlandi (2003, p. 46), vê-se que "o indivíduo é interpelado em sujeito pela ideologia para que se produza o dizer". Isso é notório no trecho seguinte: "Redigido em obediência ao novo Acordo Ortográfico e atento às normas da língua portuguesa e aos usos correntes entre os brasileiros, este dicionário traz ainda vários adendos, entre eles uma Gramática Básica". O lexicógrafo é assujeitado pelos ditames recentes do novo Acordo Ortográfico e necessita esclarecer essa situação, no próprio prefácio, numa espécie de "pacto".

Além disso, tomando como base ainda a imagem do outro, o autor afirma que, em sua obra, são incluídos gírias e estrangeirismos, que são unidades lexicais que fazem parte do vocabulário dos jovens. Ademais, o autor afirma que, na obra, há uma breve instrução de como se comportar, linguisticamente, nas redes sociais. Esse discurso também se pauta na visão imaginária do público leitor, pois se acredita que são eles os principais usuários das redes sociais. Ainda sobre essa relação entre o discurso e o outro, afirma Pâcheux: "Esse discurso-outro, quanto presença virtual na materialidade descritível da sequência, marca, do interior desta materialidade, a insistência do outro como lei do espaço social e da memória histórica, logo como o próprio princípio do real sócio-histórico" (PÊCHEUX, 2006, p. 55). E ainda:

[...] todo discurso é o índice potencial de uma agitação nas filiações sócio-históricas de identificação, na medida em que ele constitui ao mesmo tempo um efeito dessas filiações e um trabalho (mais ou menos consciente, deliberado, construído ou não, mas de todo modo atravessado pelas determinações inconscientes) de deslocamento no seu espaço: não há identificação plenamente bem sucedida, isto é, ligação sócio-histórica que não seja afetada, de uma maneira ou de outra, por uma "infelicidade" no sentido performativo do termo - isto é, no casso, por um "erro de pessoa", isto é, sobre o outro, objeto da identificação. (PÊCHEUX, 2006, p. 56-57).

Percebe-se também, no prefácio, um discurso pautado no compromisso ético e social. Por se tratar de um material didático que circula numa instituição pública, o lexicográfico enuncia a partir de um discurso a favor da educação e da inclusão social, como se vê no seguinte trecho:

Esta obra, como ferramenta de formação, educação e apoio às iniciativas de inclusão social, busca propagar conceitos e princípios éticos $[\ldots]$.

Nesse trecho, nota-se também o objetivo do material: "propagar conceitos e princípios éticos". O autor não deixa muito claro em que consiste essa propagação de conceitos e princípios éticos. No entanto, acredita-se que há uma tentativa do autor de não incluir, em seus verbetes, definições preconceituosas ou que deixem margem para isso. Esse apagamento realizado pelo autor pode ser justificado pelo desejo de receber uma boa avaliação pelo PNLD, o que mostra um discurso de políticas educacionais bem marcado.

No prefácio, também se percebeu uma influência interdisciplinar com a Sociolinguística. O autor afirma ter dado atenção especial aos significados das palavras em "diferentes regiões do Brasil, em diversos contextos, estendendo-se em empregos 
fraseológicos". Ao dar atenção especial aos significados de diferentes regiões e contextos, o lexicógrafo procura se distanciar da ideia de que existe um significado único de uma palavra. Percebe-se, assim, um discurso de inclusão, no sentido de dar voz às diversidades linguísticas do português do Brasil.

Por outro lado, ao mesmo tempo em que o autor se vale da base sociolinguística para dar atenção aos empregos regionais, ele afirma que "no verbete também não faltam chamadas para a correta flexão nominal e verbal, para a correção ortoépica e prosódica" (grifo nosso). Diante do excerto, observa-se um discurso tradicional da gramática normativa, pois o autor pauta-se ainda na noção de "certo e errado" em língua, noção essa já suplantada pelas ciências da linguagem. Não se pode desconsiderar, no entanto, que os dicionários, juntamente com as gramáticas, são instrumentos linguísticos que visam à normatização da língua (AUROUX, 2009).

Por fim, retomando a noção de relações de força, segundo a qual, conforme Orlandi (2006), o lugar social de que o indivíduo profere o discurso interfere na força da locução, nota-se a tentativa do dicionário de se fazer uso dessa "força" na enunciação. $\mathrm{O}$ sujeito autor fala a partir da sua posição-sujeito de lexicógrafo. Nessa posição, seu discurso parece ter mais força, pois se tem um imaginário de que um lexicógrafo, autor de dicionário, tem grande conhecimento sobre a língua e, principalmente, sobre sua obra.

Num olhar que transpassa o prefácio, observou-se, na contracapa da obra, uma afirmação a respeito do autor que pode servir para legitimar seu discurso e para fortalecer sua locução:

Elaborado pelo prof. Evanildo Bechara, o único representante da Academia Brasileira de Letras no novo Acordo Ortográfico. (grifo nosso)

Essa atribuição dada ao autor do dicionário, grifada no fragmento, dá força ao discurso proferido por ele e legitima seu dizer, uma vez que, no imaginário social, alguém que é representante no novo Acordo Ortográfico tem notório saber sobre a língua.

\section{Considerações finais}

Esta pesquisa pretendeu analisar o discurso do sujeito lexicográfico no prefácio do Dicionário da língua portuguesa, de Evanildo Bechara. Para tanto, lançou-se mão dos conceitos fundamentais da $\mathrm{AD}$, os quais basearam a análise feita.

No estudo do texto, observou-se a tentativa do autor de apresentar as principais vantagens de sua obra; viu-se que o discurso construído se pauta no "outro", que são os alunos do ensino médio. Além disso, inferiu-se que o discurso do sujeito lexicógrafo estava inserido num contex to de produção em que o PNLD incentiva o uso de dicionários na escola. $\mathrm{O}$ autor também constrói um discurso baseado na concepção de língua como sujeita a variações, mas, ao mesmo tempo, defende um "correto" uso da língua. E, por fim, o sujeito lexicógrafo possui força de elocução devido a sua posição de sujeito 
lexicógrafo e pelo fato de ser o único representante da Academia Brasileira de Letras no novo Acordo Ortográfico.

A posição-sujeito do lexicógrafo toma o dicionário como um objeto discursivo, é possível observar que o dicionário é um discurso inserido em um determinado período histórico, detentor de formações ideológicas e concluímos que ele é não um discurso transparente, homogêneo e detentor da verdade incontestável com relação ao sentido das palavras, pois as produções de sentidos são tomadas pela ideologia vigente, principalmente do novo Acordo Ortográfico, e o sujeito que escreve o prefácio legitima essa significação por uma necessidade de se manter no meio acadêmico de renome, no caso a ABL (Associação Brasileira de Letras).

É importante ressaltar que análise aqui empreendida, longe de ser exaustiva, não esgota as possibilidades de estudo de prefácios. Além disso, as considerações feitas a respeito do discurso do prefácio podem ou não ser validadas a partir da análise mais profunda dos verbetes, lugar onde, realmente, o autor põe em prática seu discurso. Um trabalho que compare essas informações do prefácio e as realizações nos verbetes poderia completar o estudo aqui proposto.

\section{Referências bibliográficas}

AUROUX, Sylvain. A revolução tecnologia da gramatização. $2^{\mathrm{a}}$ ed. Campinas, SP: Editora da Unicamp, 2009.

BECHARA, Evanildo. Dicionário da língua portuguesa Evanildo Bechara. Rio de Janeiro: Editora Nova Fronteira, 2011.

COURTINE, Jean-Jacques. Análise do discurso político: o discurso comunista endereçado aos cristãos. São Carlos: EdUFSCar, 2009.

CARGNELUTTI, Joceli. Uma abordagem discursiva do prefácio do livro didático Português: a constituição de um sujeito autor. ANAIS do CELSUL, 2008.

GIACOMINI, Giovana Iliada. O discurso do Dicionário contemporâneo da língua portuguesa, de Caldas Aulete: de 1881 até a atualidade. Revista Virtual de Estudos da Linguagem - ReVEL, v. 4, n. 6, março de 2006.

MUSSALIM, Fernanda. Análise do discurso. Em: ; BENTES, Anna Christina (Orgs.). Introdução à linguística: domínios e fronteiras, v. 2. $3^{\mathrm{a}}$. ed. São Paulo: Cortez, 2003.

NUNES, José Horta. Dicionários no Brasil: análise e história do século XVI ao XX. Campinas, SP: Pontes Editores; São Paulo, SP: Fapesp; São José do Rio Preto, SP: Faperp, 2006. 
OLIVEIRA, Thiago Soares de. O prefácio de Cegalla: análise sob as perspectivas sociolinguísticas e o conceito de ethos da Análise do Discurso Francesa. Vértices, Campos dos Goytacazes-RJ, v. 16, n. 1, pp. 157-171, jan./abr. 2014.

ORLANDI, Eni Puccinelli; LAGAZZI-RODRIGUES, Suzy (Orgs.). Introdução às ciências da linguagem: discurso e textualidade. Campinas, SP: Pontes, 2006. 2003.

Análise de Discurso: princípios e procedimentos. $5^{\text {a }}$. ed. Campinas, SP: Pontes,

PÊCHEUX, Michel. O discurso: estrutura ou acontecimento. Trad. Bras. $4^{\mathrm{a}}$. ed. Campinas, SP: Pontes, 2006.

RANGEL, Egon de Oliveira. Com direito à palavra: dicionários em sala de aula. Brasília: Ministério da Educação; Secretaria da Educação Básica, 2012.

Para citar este texto:

SILVA, Rodrigo Alves; HOLANDA, Layana Kelly Pereira de. Análise discursiva do Prefácio do Dicionário de Língua Portuguesa, de Evanildo Bechara. Entremeios [Revista de Estudos do Discurso], Seção Estudos, Programa de Pósgraduação em Ciências da Linguagem (PPGCL), Universidade do Vale do Sapucaí, Pouso Alegre (MG), vol. 12, p. 115-127, jan. - jun. 2016.

DOI: http://dx.doi.org/10.20337/ISSN2179-3514revistaENTREMEIOSvol12pagina115a127 